\title{
O princípio da sustentabilidade sob a ótica do transconstitucionalismo: uma análise no âmbito do recurso extraordinário $n^{0} 627.189$ (STF)
}

\author{
The principle of sustainability from the perspective of \\ transconstitutionalism: an analysis in the recourse of \\ extraordinary appeals no. 627.189 (stf) \\ MÁrCio Bonini NotARI \\ Universidade de Santa Cruz do Sul
}

Resumo O objetivo do presente trabalho é analisar o princípio da sustentabilidade na jurisprudência do Supremo Tribunal Federal, a partir da perspectiva do transconstitucionalismo. O meio ambiente ecologicamente equilibrado é objeto de inúmeros debates, em nível internacional, inclusive no campo econômico, acerca da necessidade de adoção de medidas internacionais que levem em considerações as questões ecológicas e sociais, a ponto de realizar o enquadramento legal dos países que lucram com a poluição e o desmatamento. No campo da exportação, a comunidade europeia também vem avançando na restrição ambiental aos produtos importados fruto de desmatamento. No Brasil os retrocessos na questão ambiental são sentidos na exploração de madeira ilegal e na destruição e queimadas realizadas na Amazônia. Sendo assim, a hipótese a ser desenvolvida engloba o meio ambiente como direito humano e constitucional, previstos nas normativas de direitos humanos e nas constituições modernas, mas requer uma abertura de um diálogo constitucional, levando em consideração, entrelaçamento de novas ordens jurídicas múltiplas (local, supranacional, internacional, extra estatal), na construção de novas pontes transconstitucionais. O trabalho desenvolveu, na primeira parte, o aporte teórico do transconstitucionalismo, a partir da metáfora grega de Cilas e Caríbdis; buscou delimitar os conceito e noções elementares da perspectiva transconstitucional. Buscou-se no segundo momento, analisar o princípio da sustentabilidade nas convenções internacionais de direitos humanos. Por fim, constatou-se que a ideia de sustentabilidade, a partir dos postulados do transconstitucionalismo, ainda que de forma indireta veem ganhando presença no âmbito do Supremo Tribunal Federal, a partir da análise do Recurso Extraordinário (RE)n ${ }^{\circ}$ 627.189/SP, em que foram aplicadas diversas normativas de ordem jurídicas variadas, num caso que envolveu ato de concessionária de energia elétrica na redução de eletromagnéticos prejudiciais à saúde e ambiente de trabalho. Palavras-chave: Direito Ambiental, desenvolvimento sustentável e transconstituCIONALISMO. 
AbSTRaCT The objective of the present work is to analyze the principle of sustainability in the jurisprudence of the Supreme Federal Court, from the perspective of transconstitucionalismo. The ecologically balanced environment has been the subject of numerous debates, internationally, including in the economic field, about the need to adopt international measures that take into account ecological and social issues, to the point of achieving the legal framework of countries that profit from pollution and deforestation. In the field of exports, the European community has also been advancing in the environmental restriction on imported products resulting from deforestation. In Brazil, the setbacks to the environmental issue are felt in the exploitation of illegal wood and in the destruction and burning carried out in the Amazon. Therefore, the hypothesis to be developed encompasses the environment as a human and constitutional right, as provided for in human rights regulations and in modern constitutions, but requires an opening of a constitutional dialogue, taking into account the interweaving of new multiple legal orders (local, supranational, international, extra-state), in the construction of new transconstitutional bridges. The work developed, in the first part, the theoretical contribution of transconstitutionalism, based on the Greek metaphor of Cilas and Caribdis; sought to delimit the concepts and elementary notions of the transconstitutional perspective. The second step was to analyze the principle of sustainability in international human rights conventions. Finally, it was found that the idea of sustainability, based on the postulates of tranconstitutionalism, albeit indirectly, has been gaining presence within the scope of the Supreme Federal Court, based on the analysis of Extraordinary Appeal (RE) No. 627.189 / SP, in that several different legal rules have been applied, in a case that involved an act of electric utility in the reduction of electromagnetic harmful to health and work environment.

Keywords: Environmental Law, Sustainable Development, TransconstitutionalISM

\section{INTRODUÇÃO}

Ao longo da história, o homem dominou a natureza, explorando suas riquezas sem se preocupar com o amparo da proteção do meio ambiente saudável e ecologicamente equilibrado, agindo como se as riquezas naturais fossem inesgotáveis.

No entanto, em decorrência da negligência humana, um problema que vem se tornando perene ao longo do tempo é a crise do meio ambiente, notadamente, em face da degradação ambiental e suas conseqüências com projeções globais, exigindo dos países a cooperação necessária sobre o desenvolvimento sustentável e a proteção ao meio ambiente sadio, como forma de prevenir novos danos ambientais, objetivando sua exploração de forma a preservá-lo, para as presentes e futuras gerações.

Nesse ponto, ensina Ingo Sarlet (2019, p. 371), a necessidade e urgente convergência das agendas social e ambiental em um mesmo projeto jurídico-político para o desenvolvimento humano, em face da miséria e da pobreza, bem como, a ausência de acesso aos direitos socias mais básicos (saúde, saneamento, alimentação, moradia), os quais andam juntos com a degradação ambiental, à medida que expõem as populações mais carentes, expondo duplamente sua vida e dignidade. Diante disso, o Estado e o Direito precisam se transfor- 
mar para atender aos efeitos emergenciais da crise ecológica em prol da sobrevivência da humanidade, justificando a necessidade de um Estado Socioambiental ${ }^{1}$.

Dentre outros elementos e fatores, assume particular relevância a proposta de uma proteção (e promoção) compartilhada e integrada dos direitos sociais e dos direitos ecológicos, agrupados sob o rótulo genérico de direitos fundamentais socioambientais oudireitos econômicos, sociais, culturais e ambientais (DESCA), assegurando as condições mínimas para a preservação da qualidade de vida, aquém das quais poderá ainda haver vida, mas essa não será digna de ser vivida.

O presente trabalho tem por objetivo abordar a efetivação do princípio constitucional do desenvolvimento sustentável e da proteção ambiental como forma de soluções ambientais, sob a ótica da teoria do transconstitucionalismo, em face da necessidade de abertura constitucional aos diálogos transconstitucionais na defesa dos direitos humanos e fundamentais,entre normas de Direito Internacional Público e Estatal, a partir da análise da jurisprudência do Supremo Tribunal Federal, na decisão proferida do Recurso Extraordinário (RE) no 627.189/SP.

Considerando que o presente trabalho é de natureza bibliográfica, o método de abordagem a ser adotado no seu desenvolvimento será o dedutivo, tendo pressuposto argumentos gerais, para argumentos particulares; quanto ao procedimento será analítico e o histórico crítico, procurando dar tratamento localizado à matéria objeto de estudo a partir da doutrina, jurisprudência, trabalhos acadêmicos e artigos monográficos.

\section{NOÇõES CONCEITUAIS ACERCA DO TRANSCONSTITUCIONALISMO}

A Grécia foi considerada como período cultural com uma vasta riqueza do ponto de vista cultural, a partir dos filósofos (Sócrates, Platão, Aristóteles, etc), bem como, pela história dos deuses e dos heróis da mitologia grega, estudados no campo da história, os quais servem de base para o Direito.

A contribuição de tal alvorada da filosofia se destacou também para as questões do direito e da justiça. Durante muitos séculos - e mesmo milênios - aquilo que foi o senso comum do pensamento jurídico ocidental foi consolidado a partir de uma visão geral de mundo que foi a dos romanos, que, por sua vez, hauriram-na diretamente da filosofia do direito grega (MASCARO, 2018, p. 40)

$\mathrm{Na}$ obra a Odisséia, o personagem Odisseu, que era um rei grego, foi compelido a passar pelo estreito de Messina, a qual separa a península Itálica da Sicília, para chegar em sua casa Itáca. Mesmo diante do vasto oceano, foi obrigado a passar por Cila e Caríbdis, os mais temidos monstros da mitologia grega. Cila atacou a com suas seis cabeças, enquanto Caríbdis drenou tudo o que sob a água pairava. Odisseu mirava em Caríbdis, no aguardo dos ataques de Cila, eis que saindo de uma cairia na outra.

\footnotetext{
As dimensões dos direitos humanos e fundamentais reclamam, portanto, uma compreensão integrada, desde logo incompatível com um sistema de preferências no que diz respeito á prevalência, em tese, de determinados direitos em relação a outros. Nessa perspectiva, o princípio do Estado Socioambiental assume a condição de princípio constitucional geral eestruturante, assegurando uma integração e articulação, sem que se possa falar em hierarquia, entre pilares da Democracia, do Estado de Direito, do Estado Social e da proteção do ambiente (SARLET, 2019, p. 374)
} 
Essa metáfora grega no caminho percorrido por Odisseu é a referência utilizada para os caminhos árduos do constitucionalismo sistêmico, a medida que existem gigantes poderosos a serem enfrentados, como os Constitucionalismo de ordem estatal (Caríbdis/nacionalistas), os quais entenderiam que qualquer forma de alteração constitucional seria tida como retrocesso, já que o constitucionalismo internacional (Cila), ultrapassa as fronteiras, impondo sua força e "desrespeitando" toda forma epistemológica de comunicação (TONET, 2019, p.34) $)^{2}$.

O constitucionalismo, na visão do autor, requer que se possa ultrapassar essa fronteira, pois os sistemas sociais contemporâneos e complexos são amplos produtores de normatividades jurídicas. Assim, a regulação jurídica se torna contextual amoldando-se aos contextos sociais, isto é, á sociedade. Assim, a diversidade da sociedade contemporânea tem suas origens advindas das novas realidades globais, ultrapassando os antigos conceitos Estado-Nação, criando uma normatividade sistêmica por meio dos processos sociais de comunicação, e não exclusivamente por intermédio dos modelos estatais.

Desse modo, surge a teoria do transconstitucionalismo de Marcelo Neves, com uma nova proposta de leitura acerca da complexidade do fenômeno constitucional. Esse modelo, baseia-se na ação de redes de cooperação sistêmica, isto é, na emergência de novas formas de observação sobre a emergência das ordens jurídicas internacionais, nacionais, transnacionais e supranacionais sobre os direitos fundamentais (TONET, 2019, p. 143). Nesse sentido,

\begin{abstract}
Embora as constituições estatais modernas já tenham surgido como mecanismos estruturais da racionalidade transversal entre direito e política, a semântica do constitucionalismo transversal somente tornou-se significativa em decorrência dos novos problemas com os quais a atual ordem internacional e as emergentes supranacionais e transnacionais estão confrontados cada vez mais intensamente. A esse respeito, podem ser designados como exemplo, os âmbitos da política de segurança, do comércio mundial, do direito ambiental e dos direitos humanos. Nesse contexto, a Constituição estatal é posta, inicialmente, no segundo plano, mas em outro momento, entrelaça-se com as constelações internacionais, supranacionais e transnacionais. (NEVES, 2009, p. 83)
\end{abstract}

$\mathrm{Na}$ visão do autor, a expressão transnacionalidade seria semanticamente ambígua, sendo utilizada de maneira abrangente, não se referindo apenas ás ordens, instituições e problemas transnacionais em sentido estrito, mas também ás ordens, instituições e problemas transnacionais. O núcleo básico desse conceito, embora genérico, consiste na noção de dimensões que ultrapassem as fronteiras do Estado.

O debate inclui o que segundo Neves, seria uma Constituição de cunho mundial, nos moldes republicanos a partir do modelo jusfilosófico kantiano. Nesse sentido, as lições do professor Márcio Notari (2021, p. 32): “a necessidade da paz na visão kantiana é imperativa para a ordem internacional como o Estado o é para a constituição das limitações às liberdades individuais, cuja idéia acerca da consolidação do ideário de uma federação de Estados livres".

2 Cose-te a Cila pois, amiúda o remo; Seis é melhor perder que os sócios todos." E eu: "Livre, ó deusa, da voraz Caríbdis, Como de Cila poderei vingar-me, Da ofensora dos meus?" - Tornou-me Circe: "Guerras sonhas, demente, e contra numes? Imortal, seva, tetra, inexpugnável, O remédio é fugir da imana Cila: Se tardas, junto àjunto à rocha armando o braço. Temo que novamente as seis cabeças (HOMERO, 2009, p.135) 
Para Neves, há uma tendência paradigmática para o surgimento do constitucionalismo internacional ou supranacional no plano global. A esse ponto, vão modelos de Estado Mundial, passando por concepção de política interna mundial, sob diversos enfoques, até a caracterização da Carta da ONU, que o autor denomina de "Constituição da Comunidade Internacional".

Na visão de Fernando Tonet (2019, p. 145), a Constituição continua sendo o parâmetro dentro do sistema jurídico, o qual irá determinar a relação com outros sistemas, porém sem perder a sua autonomia operacional, possibilitando um dialogo do desenvolvimento de novas estruturas sistêmicas, respeitando as diferenças no sistema mundial.

Por outro lado, o transconstitucionalismo pode ser definido como o entrelaçamento de ordens jurídicas diversas (estatais, transnacionais, internacionais e até mesmo supranacionais) em torno dos mesmos problemas de natureza constitucional.

Portanto, o fato de ordens jurídicas diferenciadas enfrentarem concomitantemente as mesmas questões de natureza constitucional pode (e deve), segundo o autor, ser traduzido como transconstitucionalismo.Com isso,em nossa sociedade hipercomplexa, estaríamos diante de um novo paradigma constitucional, que abala com as nossas pré-compreensões subjacentes (arraigadas pelo direito nacional-estatal clássico e pelo direito internacional clássico), pois problemas, por exemplo, em torno de direitos fundamentais, ou mesmo de separação e limitação de poderes (envolvendo conflitos entre o Judiciário e o Executivo de um Estado nacional contra organizações internacionais ou contra um outro Estado nacional) passam, efetivamente, a serem debatidos e discutidos por tribunais de ordens jurídicas diversas, podendo apresentar soluções distintas à luz dos contextos (e percepções) em que são analisados. (FERNANDES, 2020, p. 93)

Sobre esse aspecto, é interessante notar que não há uma negação acerca dos preceitos envolvendo o constitucionalismo clássico ${ }^{3}$, fortemente sedimentado no direito constitucional, mas uma proposta que acaba afastando a ideia de uma constituição associada de forma exclusiva a um determinado Estado, sem que possa haver um recurso a outras Constituições. O Constitucionalismo estava vinculado ao elemento territorial, na determinação coercitiva dos direitos e garantias fundamentais e limitação do poder do Estado (NEVES, 2009, p. 120)

Nessa perspectiva, com o surgimento de questões transterritoriais com implicações normativas fundamentais levaram a necessidade de abertura do constitucionalismo para além do Estado, para tratar dos problemas envolvendo direitos humanos e fundamentais; de tal modo que, sem ignorar o constitucionalismo estatal, na visão de Marcelo Neves,

3 Se a noção de que certas leis se distinguem das demais pelo seu objeto especial - a organização do próprio poder - pode retroagir a pensadores e práticas da Antiguidade, a ideia de Constituição, como a vemos hoje, tem origem mais próxima no tempo e é tributária de postulados liberais que inspiraram as Revoluções Francesa e Americana do século XVIII . É daí que surgem os atributos da Constituição como instrumento orientado para conter o poder, em favor das liberdades, num contexto de sentida necessidade de preservação da dignidade da pessoa humana. Entende-se, então, que a Declaração dos Direitos do Homem e do Cidadão, de 1789, proclamasse, no seu art. 16, que não teria constituição a sociedade em que os direitos não estivessem assegurados, nem a organização estatal em que não se definisse a separação de poderes. A compreensão da Constituição como técnica de proteção das liberdades é atributo do constitucionalismo moderno (MENDES, 2012, p. 59) 
esse modelo acabou sendo limitado para o enfrentamento desses problemas, assim como, a organização dos poderes, deixando de ser privilégio do direito constitucional do Estado.

Desse modo, o movimento constitucionalista nasceu depois do surgimento do Estado Moderno, em que a soberania estava concentrada nas mãos do estado. O constitucionalismo significa que as condutas sociais são determinadas por normas, estando a Constituição no topo da pirâmide normativa. A lei fundamental foi tomada como dogma, no sentido de que a função das normas constitucionais estava em apenas traçar os direitos fundamentais da primeira geração ${ }^{4}$ e a repartição dos poderes (AGRA, 2018, p. 64)

Aliás, essa perspectiva não mais coaduna com a atual práxis constitucional em virtude do incremento de relações transterritoriais (constitucionalismo para além do Estado). Um exemplo trabalhado pelo autor diz respeito aos direitos fundamentais (ou direitos humanos), pois essa temática, dentre outras, deixou de ser um privilégio do direito constitucional do Estado, perpassando suas fronteiras.

Assim, a transconstitucionalidade/transconstitucionalismo, em termos primários, não se preocupa em saber qual ordem se encontra uma Constituição, muito menos em trazer alguma definição como privilégio do Estado. O elemento fundamental seria demarcar os problemas que surgem em diversas ordem jurídicas, requerendo o entrelaçamento entre elas. A medida que um problema de direitos fundamentais poderá apresentar perante uma ordem internacional e transancional, ou ainda, estatal e local, perante mais de uma dessas ordens.

De tal modo, o modelo do transconstitucionalismo realiza um processo de ruptura com o dilema monismo/pluralismo, pois haveria uma pluralidade de ordens jurídicas em relação á complementariedade (identidade e alteridade). Portanto, as ordens jurídicas envolvidas na solução de um problema existente no campo do direito constitucional e no plano de sua autofundamentação, acabam reconstruindo de forma contínua sua identidade em face do entrelaçamento transconstitucional com outras ordens jurídicas, construindo pontes de transição entre diversas ordens jurídicas (NEVES, 2009, p. XXV)

É importante consignar que a Constituição e a teoria constitucional não são algo imutável dentro da interconstitucionalidade (constituições e fontes de legitimação jurídicas diversas). Ao contrário, estará abertas ás questões sociais ligadas estritamente aos problemas complexos criados no âmbito da sociedade, possibilitando novas formas de observações multiformes, que admitem concepções plurais e diferentes.

Portanto, a tese visa afastar qualquer relação de verticalização ou de subordinação entre instâncias decisórias (postura de fechamento). Sem dúvida, a busca é por intercâmbio constante, nos termos de um diálogo construtivo que vise ao aperfeiçoamento e, com isso, a decisões mais adequadas. Contra qualquer tipo de absolutização (do tipo "convergência ou resistência", ou mesmo abertura/ fechamento) afirma-se que, "o caminho mais adequado em matéria de direitos humanos parece ser o 'modelo de articulação', ou melhor, de entrelaçamento transversal entre ordens jurídicas, de tal maneira que todas se apresentem ca-

4 Na primeira geração encontram-se os direitos individuais, que traçam a esfera de proteção das pessoas contra o poder do Estado, e os direitos políticos, que expressam os direitos da nacionalidade e os de participação política, que se sintetizam no direito de votar e ser votado (BARROSO, 2018, p. 115). Na mesma linha, os direitos fundamentais de primeira geração são os direitos e garantias individuais e políticos clássicos, denominado de liberdades públicas (MORAES, 2017, p. 44) 
pazes de reconstruírem-se permanentemente mediante o aprendizado com as experiências de ordens jurídicas interessadas concomitantemente na solução dos mesmos problemas jurídicos constitucionais de direitos fundamentais ou direitos humanos" (FERNANDES,2020, p. 104)

A conclusão desse item, é de que a visão do transconstitucionalismo está em processo de desenvolvimento, em que buscando novos formatos e arranjos transversais de articulação, isto é, as pontes de transiçôes ou/conversões constitucionais para solucionar problemas/casos de natureza constitucional de maneira concomitante, tendo como núcleo a reconstrução da identidade e da alteridade.

\section{A SUSTENTABILIDADE NOS TRATADOS DE DIREITOS HUMANOS}

É consenso na doutrina que os direitos de terceira geração seriam referentes aos direitos cujo titular é a comunidade, tais como o direito ao desenvolvimento, direito à paz, direito à autodeterminação e o direito ao meio ambiente equilibrado. São também denominados de direitos de solidariedade. Conforme ensina o professor André Carvalho Ramos (2020, p. 43), " são oriundos da constatação da vinculação do homem ao planeta Terra, com recursos finitos, divisão absolutamente desigual de riquezas em verdadeiros círculos viciosos de miséria e ameaças cada vez mais concretas à sobrevivência da espécie humana".

Na mesma linha, os direitos de terceira geração, seriam aqueles assentados no princípio da fraternidade, deles fazendo parte, entre outros, o direito ao desenvolvimento, ao meio ambiente, à comunicação e ao patrimônio comum da humanidade. Tais direitos foram fortemente influenciados pela temática ambiental, nascida no mundo a partir da década de 1960, estendendo-se, depois, para outras áreas (MAZZUOLI, 2019, p. 51)

Os direitos humanos representam hoje a nova centralidade do Direito Constitucional e também do Direito Internacional. No Direito Constitucional, há a jusfundamentalização do Direito, fenômeno pelo qual as diferentes normas de um ordenamento jurídico formatam-se à luz dos direitos fundamentais. Trata-se de uma verdadeira "filtragem pro homine", na qual todas as normas do ordenamento jurídico devem ser compatíveis com a promoção da dignidade humana. (RAMOS, 2020, p. 68)

Por outro lado, a Declaração Universal dos Direitos Humanos (DUDH) de 1948 foi elaborada pela extinta Comissão de Direitos Humanos da Organização das Nações Unidas para ser uma etapa anterior à elaboração de um "tratado internacional de direitos humanos". O objetivo da Comissão era criar um marco normativo vinculante logo após a edição da DUDH. Porém, a Guerra Fria impediu a concretização desse objetivo e somente em 1966 (quase vinte anos depois da DUDH) foram aprovados dois Pactos Internacionais: o dos Direitos Civis e Políticos e o dos Direitos Sociais Econômicos e Culturais.

\footnotetext{
5 O princípio da dignidade da pessoa humana é um importante fundamento da ordem jurídica e da comunidade política. Esta ideia foi explicitamente consagrada pela Constituição brasileira em seu art. $1^{\circ}$, inciso III, que afirmou ser a dignidade da pessoa humana um dos fundamentos - o mais importante, diria eu - da República, bem como, os preâmbulos dos dois mais importantes tratados sobre direitos humanos da ONU, o Pacto dos Direitos Civis e Políticos e o Pacto dos Direito Sociais Econômicos e Culturais (SARMENTO, 2016, p. 78)
} 
O direito ao ambiente ecologicamente equilibrado é uma extensão do direito à vida, constante no art. 3..$^{\circ}$ da Declaração Universal dos Direitos Humanos (1948); trata-se do direito à sadia qualidade de vida um dos requisitos indispensáveis à existência digna do ser humano. $\mathrm{O}$ art. 3. ${ }^{\circ}$ da Declaração Universal dos Direitos Humanos dispõe que "Toda pessoa tem direito à vida, à liberdade e à segurança pessoal". Ora, quando se refere "à vida", está incluído o ambiente equilibrado, pois é uma das condições essenciais à existência da vida em toda a sua plenitude e forma.

Assim, com o nascimento das Nações Unidas, surge uma nova ordem no campo internacional instaurando um novo de conduta, no âmbito das relações internacionais, com diversas preocupações, tais como, a paz, a segurança, o desenvolvimento de relações amistosas entre países, a cooperação internacional na esfera econômica, social e cultural, o alcance de um padrão internacional de saúde, a proteção ao meio ambiente, a criação de uma nova ordem econômica internacional e a proteção internacional dos direitos humanos (MAZZUOLI, 2019, p. 70)

Artigo 12. 1, do Pacto Internacional dos Direitos Econômicos, Sociais e Culturais (PIDESC, 1966), versa sobre os Estados-partes no presente Pacto reconhecem o direito de toda pessoa de desfrutar o mais elevado nível de saúde física e mental. 2. As medidas que os Estados-partes no presente Pacto deverão adotar, com o fim de assegurar o pleno exercício desse direito, incluirão as medidas que se façam necessárias para assegurar: a) A diminuição da mortinatalidade e da mortalidade infantil, bem como o desenvolvimento são das crianças. b) A melhoria de todos os aspectos de higiene do trabalho e do meio ambiente (PIOVESAN, 2014, p. 542).

O meio ambiente, apesar de figurar esporadicamente, ao longo do tempo, em legislações esparsas, somente foi apresentado como problema global em 1972, na Conferência de Estocolmo, e manteve, aumentando ainda mais, a preocupação de seu tratamento na Conferência de 1992, no Rio de Janeiro, a ECO-92. Desde então as nações começaram a focalizar e a enquadrar a necessidade de conservação como metas a serem alcançadas para sua própria sustentabilidade (TRENNEPOHLL, 2020, p.29).

\footnotetext{
Trata-se da Conferência das Nações Unidas sobre Meio Ambiente Humano, realizada em Estocolmo, Suécia, em 1972, e ficou conhecida simplesmente por Conferência de Estocolmo. Ela foi, no nosso entender, a mais importante, pois deu origem ao direito ambiental. A partir dela, foram surgindo todos os demais instrumentos internacionais, na esfera ambiental. Dessa conferência resultou a Declaração de Princípios sobre o Meio Ambiente Humano, contendo 26 princípios. No entanto, a ideia para a sua realização foi apresentada pelo Conselho Econômico e Social da ONU em 1968, pois havia uma preocupação, na época, com a poluição do ar e a chuva ácida. Participaram da reunião 113 países e centenas de organizações governamentais e não governamentais interessadas na questão ambiental. (SIRVINSKA, 2018, p. 701)
}

Como exemplos de encontros internacionais ocorridos antes de 1972 em que se pode identificar certa preocupação com o meio ambiente, temos:Convenção de Paris (19 de março de 1902): voltava-se à proteção de aves úteis à agricultura. A Convenção de Londres (8 de novembro de 1933): voltava-se à conservação da fauna e da flora em estado natural na África, mediante a criação de parques para a proteção de espécies selvagens.Convenção de 
Washington (12 de outubro de 1940): a qual visava os mesmos objetivos da convenção de Londres, porém voltados à América (RODRIGUES, 2018, p. 601)

Malgrado as normativas históricas anteriores, a Declaração de Estocolmo, preceitua em seu Art. 1: O homem é ao mesmo tempo obra e construtor do meio ambiente que o cerca, o qual the dá sustento material e lhe oferece oportunidade para desenvolver-se intelectual, moral, social e espiritualmente. No mesmo dispositivo, acresce que em larga e tortuosa evolução da raça humana neste planeta chegou-se a uma etapa em que, graças à rápida aceleração da ciência e da tecnologia, o homem adquiriu o poder de transformar, de inúmeras maneiras e em uma escala sem precedentes, tudo que o cerca. Os dois aspectos do meio ambiente humano, o natural e o artificial, são essenciais para o bem-estar do homem e para o gozo dos direitos humanos fundamentais, inclusive o direito à vida.

O Pacto de San José da Costa Rica (1966), prevê em seu Artigo 11, o Direito a um meio ambiente sadio 1. Toda pessoa tem direito de viver em meio ambiente sadio e a contar com os serviços públicos básicos. 2. Os Estados-Partes promoverão a proteção, preservação e melhoramento do meio ambiente.

A Carta Africana do Direito dos Povos (1981), nos artigos 15 a 26 traduzem o catálogo dos direitos econômicos, sociais, culturais e ambientais e os direitos dos povos, incluindo o direito ao trabalho sob condições justas e equitativas; o direito à saúde; o direito à educação; o direito de participar da vida cultural; o direito à proteção da família, como guardiã da moral e dos valores tradicionais reconhecidos pela comunidade; o direito à igualdade e autodeterminação dos povos; o direito dos povos de dispor de suas riquezas e de seus recursos naturais; o direito ao desenvolvimento econômico, social e cultural; o direito à paz e à segurança; o direito a um meio ambiente satisfatório (PIOVESAN, 2019, p. 273)

A noção de desenvolvimento sustentável, guarda conexão direta com o princípio do Estado Socioambiental, foi objeto de reconhecimento internacional no âmbito da Comissão Mundial sobre Meio Ambiente e Desenvolvimento das Nações Unidas, designadamente por meio do Relatório Nosso Futuro Comum (1987), tendo sido definida como sendo aquele que atende às necessidades do presente sem comprometer a possibilidade de as gerações futuras atenderem a suas próprias necessidades. Incorporando o conceito adotado pela assim chamada Comissão Bruntland (SARLET, 2019).

O Mercosul foi criado pelo Tratado de Assunção (1991) com a finalidade de instituir um mercado comum entre Argentina, Brasil, Paraguai e Uruguai, no Preâmbulo do Tratado se lê que relativamente aos Estados-partes "a ampliação das atuais dimensões de seus mercados nacionais, através da integração, constitui condição fundamental para acelerar seus processos de desenvolvimento econômico com justiça social", e esse objetivo "deve ser alcançado mediante o aproveitamento mais eficaz dos recursos disponíveis, a preservação do meio ambiente (SARLET, 2019).

O Artigo 15, da Carta Americana, também denominada de Carta da Organização dos Estados Americanos (OEA, 2001), elenca que o exercício da democracia facilita a preservação e o manejo adequado do meio ambiente. É essencial que os Estados do Hemisfério implementem políticas e estratégias de proteção do meio ambiente, respeitando os diversos tratados e convenções, para alcançar um desenvolvimento sustentável em benefício das futuras gerações ${ }^{6}$. Assim, vale citar, o Plano Nacional de Direitos Humanos III (2002):

6 http://www.oas.org/OASpage/port/Documents/Democractic_Charter.htm. Data de acesso: 21.05.2021. 
O PNDH-III a própria dinâmica da historicidade dos direitos humanos, que refletem um construído axiológico, a partir de um espaço simbólico de luta e ação social voltado à proteção da dignidade humana. Direito ao meio ambiente, direito ao desenvolvimento sustentável, direito à verdade, direitos dos idosos, direito à livre orientação sexual, direito aos avanços tecnológicos, entre outros, são temas que emergem na agenda contemporânea de direitos humanos. O Programa é reflexo das complexidades da realidade brasileira no campo dos direitos humanos, a conjugar uma pauta pré-republicana (por exemplo, o combate e a prevenção ao trabalho escravo) com desafios da pós-modernidade, por exemplo, o fomento à implementação de tecnologias socialmente inclusivas e ambientalmente sustentáveis. ((PIOVESAN, 2012, p. 270)

Conforme ensina Marcelo Neves, a noção de direitos do homem ou direitos humanos, disntiguia-se pelo fato da cidadania, surgida as primeiras revoluções liberais, que significava direitos de toda e qualquer pessoa humana; na segunda, dizia respeito a cidadania enquanto membros de uma comunidade política e, de forma mais precisa, do Estado, o que Hannah Arendt, conceituava como direito a ter direitos?

Lastreado na perspectiva do sociólogo Niklas Luhman, o autor elenca na sua proposta que os direitos humanos sejam definidos como expectativas normativas de inclusão jurídica de toda e qualquer pessoa na sociedade mundial e, portanto de acesso universal ao direito enquanto subsistema social. Isso porque, a inclusão de pessoas em um sistema funcional, no direito, está vinculada á manutenção de uma ordem diferenciada de comunicação na sociedade mundial e, portanto, com a diferenciação do direito (NEVES, 2009, p. 253)

Sendo assim, na visão do autor, os direitos humanos e fundamentais, dizem respeito a inclusão da pessoa e a diferenciação da sociedade, onde seus conteúdos acabam coincidindo. A diferença encontara-se nas pretensões de validade; os direitos fundamentais tem validade em uma ordem constitucional determianda, por outro lado, os direitos humanos, pretendem valer para um sistema jurídico mundial de níveis múltiplos, isto é, para qualquer ordem jurídica existente na sociedade mundial, não apenas internacional.

De tal modo que, muito embora os direitos humanos tenham surgido vinculados á idéia do direito constitucional estatal, eles perpassam todos os níveis de ordens jurídicas no sistema jurídico mundial de níveis múltiplos (estatais, supranacionais, transnacionais e locais), constituindo uma questão central do transconstitucionalismo.

\section{O PRincípio da Sustentabilidade na ConstituiçÃo Federal sob a ÓTICA DO TRANSCONSTITUCIONALISMO}

O Direito Ambiental dispõe de uma legislação, programas e ações de excelência, contudo sua aplicabilidade ainda é utópica no Brasil. E a proteção ao meio ambiente vem ocu-

Ensina Celso Lafer, que na visão arendtiana, é justamente para garantir que o dado da existência seja reconhecido e não resulte apenas do imponderável da amizade, da simpatia ou do amor no estado de natureza, que os direitos são necessários. É por essa razão que Hannah Arendt realça, a partir dos problemas jurídicos suscitados pelo totalitarismo, que o primeiro direito humano é o direito a ter direitos. Isso significa pertencer, pelo vínculo da cidadania, a algum tipo de comunidade juridicamente organizada e viver em uma estrutura na qual se é julgado por ações e opiniões, por obra do princípio da legalidade (LAFER, 1988, p. 153-154) 
pando lugar de destaque, devido ás consequências de uma degradação ambiental local que chegarão a repercutir sobre todo o globo terrestre, vindo a ocasionar danos ambientais para uma pluralidade de ordens jurídicas, repercutindo como um problema de caráter constitucional e com conjectura internacional (ROCHA, SCHERBAUM, 2019, p. 19)

Para Sirvinskas (2018, p. 113), o princípio do direito humano decorre do primeiro princípio da Conferência das Nações Unidas sobre Meio Ambiente e Desenvolvimento, aprovado em Congresso realizado no Rio de Janeiro em 1992, onde se reza que os seres humanos estão no centro das preocupações relacionadas com o desenvolvimento sustentável.

Têm direito a uma vida saudável e produtiva, em harmonia com o meio ambiente. Necessariamente, verifica-se que tal princípio possui viés constitucional, assim como fulcro em documentos internacionais.

O segundo, por sua vez, trata-se do valoroso princípio do desenvolvimento sustentável, expressão última que surgiu em meados de 1987, tomando relevo no Relatório de Brundtland - documento da ONU - e tornando-se, posteriormente, matéria principiológica, estabelecendo, portanto, a conciliação da proteção do meio ambiente com o desenvolvimento socioeconômico, almejando, em suma, a melhoria da qualidade de vida do homem, com observância à gestão racional dos recursos naturais.

Na visão Amado (2017, p. 63), o Princípio do Desenvolvimento Sustentável é aquele que atende as necessidades do presente sem comprometer a possibilidade da existência digna das gerações futuras, sendo possível melhorar a qualidade de vida dos vivos. Salienta ainda, que além da acepção econômico ambiental, pressupõe o desenvolvimento dos povos, no combate á pobreza e justa distribuição de riqueza no mundo.

É, portanto, a partir desse princípio que se discutem os modelos de desenvolvimento sustentável, com embasamentos legais pátrios contidos nos artigos 170, inciso VI, e 225, da Relatório de Brundtland é o documento intitulado "Nosso Futuro Comum" (Our Common Future), publicado em 1987. Nesse documento o desenvolvimento sustentável é concebido como: o desenvolvimento que satisfaz as necessidades presentes, sem comprometer a capacidade das gerações futuras de suprir suas próprias necessidades.

Os direitos de terceira dimensão têm como principal vetor o direito à fraternidade, fraternidade de direitos do gênero humano. São exemplos típicos de prerrogativas de terceira dimensão: direito ao desenvolvimento, à paz, ao meio ambiente equilibrado, ao patrimônio histórico, artístico e cultural, à autodeterminação dos povos, à solidariedade, ao desenvolvimento, à proteção dos consumidores, direitos dos hipossuficientes, à preservação da intimidade etc.

Alguns autores, como Walber de Moura Agra (2018) denominam de direitos pós-materiais. Na esfera do direito internacional, tem incidência nas relações entre os Estados, estimulando relações de coordenação, em que a ajuda e a cooperação dos países mais ricos aos países mais pobres sejam estimuladas. Assim, os sujeitos da relação jurídica e, portanto, dos direitos de terceira dimensão não envolve o cidadão/cidadão, Estado/cidadão, mas passando a ser considerado difuso, de natureza coletiva, mais precisamente, transindividual. O destinatário é o homem em termos de gênero humano, enfocado sob um prisma coletivo (AGRA, 2018)

Se o destinatário é coletivo, a responsabilidade para a sua concretização também é coletiva, não dependendo apenas da atuação estatal para assegurar a todos a consecução 
desses direitos. O cidadão tem especial participação na sua efetivação. Os direitos de terceira dimensão ultrapassam os limites territoriais do país, podendo-se falar na globalização desses direitos, como condição para a sua realização fática.Segundo o Supremo Tribunal Federal:

O direito à integridade do meio ambiente - típico direito de terceira geração - constitui prerrogativa jurídica de titularidade coletiva, refletindo, dentro do processo de afirmação dos direitos humanos, a expressão significativa de um poder atribuído, não ao indivíduo identificado em sua singularidade, mas, num sentido verdadeiramente mais abrangente, à própria coletividade social. Enquanto os direitos de primeira geração (direitos civis e políticos) - que compreendem as liberdades clássicas, negativas ou formais - realçam o princípio da liberdade e os direitos de segunda geração (direitos econômicos, sociais e culturais) - que se identificam com as liberdades positivas, reais ou concretas - acentuam o princípio da igualdade, os direitos de terceira geração, que materializam poderes de titularidade coletiva atribuídos genericamente a todas as formações sociais, consagram o princípio da solidariedade e constituem um momento importante no processo de desenvolvimento, expansão e reconhecimento dos direitos humanos, caracterizados, enquanto valores fundamentais indisponíveis, pela nota de uma essencial inexauribilidade ${ }^{8}$. [MS 22.164, rel. min. Celso de Mello, j. 30-10-1995, P, DJ de17-11-1995.]

Compreende-se, nessa linha, indo mais além, da classificação tradicional, que os direitos da terceira dimensão, na visão de Ingo Sarlet (2019, p. 405), "são denominados usualmente como direitos de solidariedade ou fraternidade, de modo especial em face de sua implicação transindividual ou mesmo universal (transnacional)". Assim, na visão do autor, esses direitos exigem esforços e responsabilidades em nível mundial para sua efetivação.

Em pertinência à Constituição Federal Brasileira de 1988, constata-se a tutela do direito ambiental como inovação na ordem jurídica das Cartas Magnas até então elaboradas, uma vez que seu artigo 225, o direito a um meio ambiente ecologicamente equilibrado, colocando-o, destacadamente, em capítulo próprio e relativo à ordem social. Foi nesta Constituição que a expressão meio ambiente de fato apareceu, objetivando aliar a preservação ecológica à qualidade de vida do cidadão, caracteres esses que se fundem em um direito superior, qual seja, o direito à vida.Ao definir de meio ambiente,

"O conceito legal e doutrinário é tão amplo que nos autoriza a considerar de forma praticamente ilimitada a possibilidade de defesa da flora, da fauna, das águas, do solo, do subsolo, do ar, ou seja, de todas as formas de vida e de todos os recursos naturais, como base na conjugação do art. 225 da Constituição com as Leis números 6.938/81 e 7.347/85. Estão assim alcançadas todas as formas de vida, não só aquelas da biota (conjunto de todos os seres vivos de uma região) como da biodiversidade (conjunto de todas as espécies de seres vivos existentes na biosfera, ou seja, todas as formas de vida em geral do planeta), e até mesmo está protegido o meio que as abriga ou lhes permite a subsistência". (MAZZILLI, 2005, pp. 142-143)

8 Disponível em http://www.stf.jus.br/portal/constituicao. Data de acesso: 21.05.2021. 
A Constituição brasileira de 1988, além de possuir um capítulo próprio para as questões ambientais (Capítulo VI, do Título VIII), trata, ao longo de diversos outros artigos, das obrigações da sociedade e do Estado brasileiro para com o meio ambiente. A fruição de um meio ambiente saudável e ecologicamente equilibrado foi erigida em direito da coletividade pela ordem jurídica vigente, o que se revela num notável avanço para a construção de um sistema de garantias da qualidade de vida dos cidadãos.

A Lei Fundamental reconhece que as questões pertinentes ao meio ambiente são de vital importância para o conjunto de nossa sociedade, seja porque são necessárias para preservação de valores que não podem ser mensurados economicamente, seja porque a defesa do meio ambiente é um princípio constitucional geral que condiciona a atividade econômica, conforme dispõe o artigo 170, inciso VI, da CF, em busca de um desenvolvimento sustentável.

Por outro lado, incorporando o conceito adotado pela assim chamada Comissão Bruntland, o Princípio n. 4 da Declaração do Rio sobre Meio Ambiente e Desenvolvimento de 1992 veio a estabelecer que, "a fim de alcançar o desenvolvimento sustentável, a proteção do ambiente deverá constituir-se como parte integrante do processo de desenvolvimento e não poderá ser considerada de forma isolada" (SARLET, 2019, p. 379)

A ideia de sustentabilidade encontra-se, portanto, numa primeira fase mais diretamente vinculada à proteção do ambiente, já que manter (e, em alguns casos, recuperar) o equilíbrio ambiental implica o uso racional e harmônico dos recursos naturais, de modo a, por meio de sua degradação, também não esgotá-los, tudo de modo a assegurar a sobrevivência e qualidade de vida das futuras gerações.

Assim, os preceitos ambientais constitucionais exigem, para sua concretização, que normas infraconstituicionais estabeleçam regras e penalizem condutas, bem como incitem o Poder Público a criar mecanismos essenciais à preservação ambiental, através de programas governamentais de atuação ou, até mesmo, de conscientização da coletividade, uma vez que o discernimento, responsabilidade e colaboração desta última, são figuras fundamentais para a consolidação da preservação dos recursos naturais.

Em caracterização específica, Paulo de Bessa Antunes (2004, p. 31) esclarece que:Os princípios do Direito Ambiental estão voltados para a finalidade básica de proteger a vida, em qualquer forma que esta se apresente, e garantir um padrão de existência digno para os seres humanos desta e das futuras gerações, bem como de conciliar os dois elementos anteriores com o desenvolvimento econômico ambientalmente sustentado.

É indubitável que o homem, em princípio, precisa ter elucidada a sua relação com a Terra, com o meio ambiente em si. Destaca-se que a preservação dos recursos naturais passou a ser preocupação mundial, não tão-somente devido às ameaças e catástrofes da natureza a que estamos expostos, mas também, pela necessidade de pensarmos nas gerações futuras.

Nessa seara, embora existam inúmeras legislações, tanto na esfera nacional como na internacional que abordem as questões ambientais, estas se mostram insatisfatórias, visto que que não são efetivas no combate à destruição de recursos naturais que são dilacerados, inclusive, pela indústria do consumo (DALLACORT; LUZ;SOBRINHO, 2020, p. 857)

Para Marcelo Neves (2009, p. 63), “a experiência marcante do transconstitucionalismo pluridimensional dos direitos humanos, as normas de direito convencionais do direito 
internacional e a jurisprudência dos tribunais, são usuais". O autor cita, a titulo de exemplo, o caso do Habeas Corpus 82.424/RS ${ }^{9}$ (Hatespeech), sobre a publicação de livro negando a existência do holocausto, em que são utilizadas inúmeros fundamentos de direito internacional público.

$\mathrm{O}$ autor salienta que não se trata apenas de simples convergência entre os Art. $5^{\circ} \S 2$, $\S 3$ e $\S 4$ da Constituição Federal, que versam sobre direitos humano, mas sim de um modelo de articulação, ou na perspectiva transconstitucional, de um entrelaçamento quanto a transversalidade entre ordens jurídicas capazes de reconstruirem-se concomitamente nas soluções de problemas constitucionais (jurídicos), entre direitos humanos e fundamentais (NEVES, 2009, p. 264).

Outrossim, a integração sistêmica cada vez maior da sociedade mundial levou à desterritorialização de problemas-caso jurídico-constitucionais, que, por assim dizer, emanciparam-se do Estado. É isso que ocorre com o meio ambiente e o desenvolvimento sustentável. As consequências de uma degradação ambiental local chegarão a repercutir sobre todo o globo terrestre, vindo a ocasionar danos ambientais para uma pluralidade de ordens jurídicas, repercutindo como um problema de caráter constitucional e com conjectura internacional (ROCHA, SCHERBAUM, 2019, p. 25)

Um caso passível de análise acerca da presença, ainda que de forma tímida, do dialogo entre transconstitucional e a tutela do meio ambiente, ocorreu no caso envolvendo o Recurso Extraordinário interposto pela ELETROPAULO Metropolitana - Eletricidade de São Paulo S/A contra decisão emanada do E. Tribunal de Justiça de São Paulo/SP.

A controvérsia de natureza constitucional em que a ELETROPAULO, foi condenação a reduzir a intensidade dos campos eletromagnéticos de baixa frequência, em face do potencial rico de câncer a população.

No voto do eminente Ministro Celso de Mello, embora o relator da ação seja o Ministro Dias Toffoli, restou consignado que o direito á integridade do meio ambiente possui prerrogativa jurídica de titularidade, o que reflete, no processo de afirmação dos direitos humanos, que expressam o poder deferido, não a um indivíduo no singular, mas em caráter mais amplo, referindo - se á coletividade social.

O acórdão ora recorrido tem como suporte legitimador o princípio da precaução, cuja noção conceitual, como sabemos, foi definida pelo Princípio 15 da Declaração do Rio (ECO/92), assim enunciado: "Para que o ambiente seja protegido, serão aplicadas pelos Estados, de acordo com as suas capacidades, medidas preventivas. Onde existam ameaças de riscos sérios ou irreversíveis não será utilizada a falta de certeza científica total como razão para o aditamento de medidas eficazes em termos de custo para evitar a degradação ambiental. A importância fundamen-

9 O discurso de ódio foi objeto de análise em momento anterior, pelo Supremo Tribunal Federal, nos autos do Habeas Corpus n. 82.424-2. Nesse caso, houve incitamento contra os judeus pelo jornalista Siefert Ellwanger, O crime está previsto no Art. 5, XLII, da CF, que elenca que a prática de racismo constitui crime inafiancável e imprescrítivel, sujeito a penas de reclusão nos termos da lei. Vale frisar que, a Constituição de 1988 reafirmou o comprometimento brasileiro de combate à discriminação racial ao dispor, no seu art. $4^{\circ}$, VIII, o repúdio ao racismo como um dos princípios que regem as relações internacionais brasileiras. Também, no mesmo dispostivo, no Art. 4, II, a prevalência dos direitos humanos. (LAFER, 2005, p. 33). 
tal desse princípio de Direito Ambiental - a que já se referia a Carta Mundial da Natureza (Princípio 11, "b”), adotada em 1982 pela Assembleia Geral das Nações Unidas. Evidencia-se ante a circunstância de que diversos outros documentos internacionais, tais como a Convenção-Quadro das Nações Unidas sobre Mudança do Clima e a Convenção sobre Diversidade Biológica, também vieram a contemplar esse postulado essencial. Com efeito, o princípio da precaução, que tem suporte em nosso ordenamento interno (CF, art. 225, § $1^{\circ}$, V, e Lei $n^{\circ} 11.105 / 2005$, art. $1^{\circ}$, "caput") e, também, em declarações internacionais (como a Agenda 21, Princípio 15, que resultou da Conferência do Rio/92), incidirá como advertem doutrina e jurisprudência, sempre que houver probabilidade de concretização de dano em consequência de atividade identificada por sua potencialidade lesiva. Caso tal ocorra, impor-se-á, então, ao Estado, com apoio em referido postulado, a adoção de medidas de índole cautelar destinadas a preservar a incolumidade do meio ambiente e a proteger, desse modo, a integridade da vida e da saúde humanas. (STF, RECURSO EXTRAORDINÁRIO 627.189 SÃO PAULO, Disponível em http://www.stf.jus.br/arquivo/cms/noticiaNoticiaStf/anexo/RE627.189SPVoto.pdf. Data de acesso. 21 mai.2021)

No voto do ministro, restou destacado, além dos preceitos constitucionais (Art. 225, Caput, e parágrafo $1 .^{\circ}, \mathrm{V}$, ambos da Constituição Federal), houve uma discussão lato sensu, sobre precedentes não apenas de natureza constitucional, mas de legislação de estados estrangeiros, tais como, a Carta Mundial da Natureza, a Convenção-Quadro das Nações Unidas sobre Mudança do Clima e a Convenção sobre Diversidade Biológica, que concretizam a incidência da legislação de estados estrangeiros.

Ainda, no voto constou a menção a sentença lavrada pelo Tribunal de Justiça do Estado de São Paulo, na qual citamos parte do trecho, referente á questão envolvendo o princípio da sustentabilidade e da precaução:

\begin{abstract}
A documentação produzida pela ELETROPAULO, bem como o parecer de seu assistente técnico, tão-somente demonstraram a inegável controvérsia na comunidade científica. Não afastaram a existência de risco dos campos eletromagnéticos para a saúde das pessoas. O princípio da precaução é corolário da diretiva constitucional que impõe a preservação do meio ambiente, que por sua vez está indissociavelmente ligada à proteção da vida. Como pontua o relatório do $5^{\circ}$ Programa da Comunidade Europeia de política e ação em matéria de ambiente e desenvolvimento sustentável, que ora se reitera de forma expressa: 'não podemos dar-nos ao luxo de esperar ... E estarmos errados!'. Frise-se: o que está em jogo é a própria vida humana. Os estudos colacionados aos autos demonstram que a radiação não-ionizante decorrente das linhas de transmissão de energia elétrica está ligada direta ou indiretamente à incidência de algumas doenças, principalmente o câncer. (STF, RECURSO EXTRAORDINÁRIO 627.189 SÃO PAULO, Disponível http://www.stf.jus.br/arquivo/cms/noticiaNoticiaStf/ anexo/RE627.189SPVoto.pdf. Acesso em:. 21 mai.2021)
\end{abstract}

Nesse sentido, em relação ao princípio da sustentabilidade, o qual está diretamente vinculado ao princípio da precaução, fez-se referência ao Relatório do $5 .^{\circ}$ Programa da Comunidade Européia de política em matéria de meio ambiente, em face dos riscos eletro- 
magnéticos que seriam produzidos á saúde das pessoas, ou seja, o meio ambiente também está ligado ao direito á vida.

Sendo assim, ainda que em caráter "embrionário", o Supremo Tribunal Federal, vem realizando o que Marcelo Neves denomina de abertura constitucional para além do Estado, tendo em vista a transterritorialização dos problemas jurídicos constitucionais e as diversas ordens para as quais são relevantes. No transconstitucionalismo entre direito internacional público e direito estatal, surgem cada vez mais problemas envolvendo ordens jurídicas diversas (NEVES, 2009, p. 132)

Para além da regulação do princípio do desenvolvimento sustentável (ou, simplesmente, sustentabilidade), importa sublinhar que existe uma tensão dialética permanente entre o objetivo da proteção ambiental e o desenvolvimento socioeconômico, de modo que a opção por uma perspectiva integrada - socioambiental - implica ainda maior (e também mais complexa e tensionada) articulação com uma concepção de constituição econômica, que, portanto, não pode ser concebida como um núcleo isolado no contexto mais amplo da ordem constitucional (SARLET, 2019, p. 389)

Ora, o Estado deixou de ser o local privilegiado de solução de problemas constitucionais, ainda que mantenha um lugar indispensável e fundamental. Por outro lado, a desterritorialização dos problemas jurídicos constitucionais, com a criação de novas pontes normativas transconstitucionais, de certa forma, acabaram por se emancipar do Estado, como vem ocorrendo com a tutela do meio ambiente e da sustentabilidade.

\section{CONSIDERAÇões FINAIS}

Mister a luz de tais constatações, o presente trabalho utilizou a metáfora grega de Cilas e Caribdis , para mostrar a existência dos itinerários das dificuldades a serem enfrentadas na edificação do transconstitucionalismo, na medida em que busca como Odisseu, superar as fronteiras, em relação aos limites impostos pelo constitucionalismo estatal, para abertura do constitucionalismo em uma perspectiva internacional, ultrapassando limites e fronteiras, dos padrões da teoria constitucional (estado liberal clássico), baseado nos limites territoriais do estado e na coerção dos direitos fundamentais como limitadores do poder estatal.

Nesse ponto, é importante consignar, que os problemas jurídicos, em relação aos direitos humanos e fundamentais, vem se apresentando em um plano de transnacionalidade, o que implica uma necessidade de entrelaçamento de novos horizontes do direito, para além do locus central de produção normativa, isto é, a Constituição como instrumento legal de transformação jurídica, abrindo espaço para outras regras de direito que estão surgindo de outros sistemas, conforme restou demonstrado a partir das normativas internacionais acerca de direitos humanos.

Conforme analisado a partir do julgado do Supremo Tribunal Federal, a perspectiva transconstitucional implica no reconhecimento de que diversas ordens jurídicas entralaçadas na solução de uma demanda constitucional envolvendo os direitos humanos ou fundamentais, o que requer a busca de formas transversais no caso concreto, a partir de sua compreensão, limites e possibilidades de contribuição para solucioná-lo, como ocorreu no julgado Recurso Extraordinário 627.189/SP, em que se vislumbrou o transconstitucionalismo no julgamento. 
O presente trabalho sinaliza, portanto, a importância da abordagem transconstitucional e do diálogo entre as fontes múltiplas de direitos humanos, servindo como alternativa eficaz para a tutela do meio ambiente ecologicamente equilibrado (princípio da sustentabilidade), em razão da universalidade desse bem jurídico, que transcende fronteiras, além de constituir, num direito difuso e transindividual de terceira dimensão.

\section{REFERÊNCIAS}

AGRA, Walber de Moura.Curso de Direito Constitucional.- 9. ed. Belo Horizonte: Fórum, 2018.

AMADO, Frederico. Direito Ambiental. 5 Edição: Salvador: Editora Juspodvim, 2017.

ANTUNES, Paulo Bessa Antunes. Direito ambiental. Imprenta: Rio de Janeiro, Lumen Juris, 2004.

BARROSO, Luís Roberto.Curso de direito constitucional contemporâneo: os conceitos fundamentais e a construção do novo modelo. - 7. ed. - São Paulo: Saraiva Educação, 2018 .

DALLACORT, Luis Ângelo; LUZ, Ariane Faverzani da; PILAU SOBRINHO, Liton Lanes. $O$ transconstitucionalismo como uma alternativa para a problemática ambiental nas sociedades modernas. Revista Eletrônica Direito e Política, Programa de Pós-Graduação Stricto Sensu em Ciência Jurídica da UNIVALI, Itajaí, v.15, n.3, $3^{\circ}$ quadrimestre de 2020.

FERNANDES, Bernardo Gonçalves. Curso de Direito Constitucional.12. ed. rev., atual, e ampl. - Salvador: Ed. JusPodivm, 2020.

HOMERO. Odisséia. Tradução de Manoel Odorico Mendes (1799-1864).Atena Editora São Paulo, 2009.

LAFER, Celso. A Reconstrução dos Direitos Humanos: um diálogo com o pensamento de Hannah Arendt. São Paulo: Cia. das Letras, 1988.

. A Internacionalização dos direitos humanos. Constituição, racismo e relações internacionais. Barueri - SP: Manole, 2005.

MASCARO, Alysson Leandro.Filosofia do direito. - 6. ed. rev. e atual. - São Paulo: Atlas, 2018.

MAZZILLI, Hugo Nigro. A Defesa dos Interesses Difusos em Juízo. 18. ed. São Paulo: Saraiva, 2005. 
MAZZUOLI, Valério de Oliveira. Curso de direitos humanos. -6. ed. - Rio de Janeiro: Forense; São Paulo: MÉTODO, 2019.

MORAES, Alexandre de. Direito constitucional. - 33. ed. rev. e atual. até a EC no 95, de 15 de dezembro de 2016 - São Paulo: Atlas, 2017.

NEVES, Marcelo. Transconstitucionalismo. Imprenta: São Paulo, Martins Fontes, 2009.

NOTARI, Márcio Bonini. Introdução à Filosofia do Direito: Kant, Marx, Engels e Hannah Arendt. Rio de Janeiro: Letras e Versos, Rio de Janeiro, 2021.

PIOVESAN, Flávia. Direitos humanos e justiça internacional: um estudo comparativo dos sistemas regionais europeu, interamericano e africano; prefácio de Celso Lafer. - 9. ed. rev. e atual. - São Paulo : Saraiva Educação, 2019

. Direitos Humanos e o direito constitucional internacional. - 14. ed., rev. e atual. SãoPaulo: Saraiva, 2014.

. Temas de Direitos Humanos. 5. ed. - São Paulo: Saraiva, 2012.

RAMOS, André de Carvalho. Curso de direitos humanos. São Paulo: Saraiva, 2020.

ROCHA, Leonel Severo. SCHERBAUM, Júlia Francieli Neves. O Manifesto da Transconstitucionalidade para Preservação do Meio Ambiente. Revista Eletrônica do Curso de Direito da UFSM www.ufsm.br/revistadireito v. 14, n. 3 / 2019.

RODRIGUES, Marcelo Abelha.Direito ambiental esquematizado. - 5. ed. - São Paulo : Saraiva Educação, 2018.

SARLET, Ingo Wolfgang.Curso de direito constitucional. - 8. ed. - São Paulo : Saraiva Educação, 2019.

SARMENTO, Daniel. Dignidade da pessoa humana: conteúdo, trajetórias e metodologia. Belo Horizonte: Fórum, 2016.

SIRVINSKAS, Luís Paulo.Manual de direito ambiental. - 16. ed. - São Paulo : Saraiva Educação, 2018.

TONET, Fernando. Entre Cila e Caríbdis: o árduo caminho do constitucionalismo sistêmico. São Leopoldo, Editora Unisinos: 2019.

. Reconfigurações do constitucionalismo. Rio de Janeiro, Lumen Juris, 2019. 
TRENNEPOHL, Terence. Manual de direito ambiental. - 8. ed. - São Paulo : Saraiva Educação, 2020.

ORGANIZAÇÃO DOS ESTADOS AMERICANOS AMERICANOS (OEA). Disponível em http://www.oas.org/OASpage/port/Documents/Democractic Charter.htm. Acesso em: 21 mai. 2021.

SUPREMO TRIBUNAL FEDERAL Disponível em http://www.stf.jus.br/arquivo/cms/noticiaNoticiaStf/anexo/RE627.189SPVoto.pdf. Acesso em: 21 mai. 2021.

\section{DAdO DO AUTOR}

\section{MÁrCio Bonini Notari}

Mestre em Direito pela Universidade de Santa Cruz do Sul. Especialização em Direito e Processo do Trabalho pela Anhanguera-RS. Bacharel em direito pela Universidade Católica de Pelotas. E-mail: marciobnotari@gmail.com

Submetido em: 8-6-2021

Aceito em: 23-9-2021 